\title{
Rhizosphere Acidification is Not Part of the Strategy I Iron Deficiency Response of Vaccinium arboreum and the Southern Highbush Blueberry
}

\author{
Gerardo H. Nunez, James W. Olmstead, and Rebecca L. Darnell ${ }^{1}$ \\ Horticultural Sciences Department, University of Florida, P.O. Box 110690, \\ Gainesville, FL 32611
}

Additional index words. $\mathrm{pH}$, soil adaptation, $\mathrm{H}^{+}$-ATPase, chlorosis, Vaccinium corymbosum

\begin{abstract}
Vaccinium arboreum (VA) is a wild blueberry species that exhibits wider soil pH tolerance and greater ability for iron and nitrate uptake than cultivated Vaccinium species, including southern highbush blueberry (SHB, V. corymbosum interspecific hybrids). The ability of VA and SHB to respond to iron deficiency by rhizosphere acidification was investigated. Rooted cuttings of the VA genotype FL09-502 and SHB 'Emerald' were transplanted to a hydroponic system filled with complete nutrient solution. After 14 days of acclimation at $45 \mu M$ iron, plants were transferred to unbuffered nutrient solutions containing 90 or $10 \mu \mathrm{M}$ iron. 'Emerald' and FL09-502 plants grown in $10 \mu \mathrm{M}$ iron exhibited less iron uptake and lower chlorophyll, total iron, and active iron contents than plants grown in $90 \mu \mathrm{M}$ iron. Generally, there were no species-level differences in iron or nitrate uptake. Neither FL09-502 nor 'Emerald' acidified the rhizosphere in either the nutrient solution or in a gel-based assay, regardless of external iron concentration. A screen of 18 additional genotypes of $\mathrm{VA}$ and SHB confirmed that this response is absent in these taxa. Thus, rhizosphere acidification is not part of the iron deficiency response of SHB and VA. In addition, the ability to acidify the soil is not likely to be responsible for the wider soil $\mathrm{pH}$ tolerance of VA.
\end{abstract}

Iron is an essential element for plant growth but its uptake by plants can be limited by biotic and abiotic factors (Kim and Guerinot, 2007). Dicots and nongraminaceous monocots respond to iron limitation through strategy I iron uptake. This strategy comprises the coordinated action of three complementary processes functioning at the plasma membrane (PM) of root epidermal cells: a) rhizosphere acidification, b) iron reduction, and c) transmembrane iron transport (Jeong and Conolly, 2009).

Rhizosphere acidification results from the action of PM-bound $\mathrm{H}^{+}$-ATPases that extrude protons from the symplastic space into the rhizosphere (Kim and Guerinot, 2007). This facilitates iron uptake by increasing the solubility of iron-containing compounds in the soil (Lemanceau et al., 2009), providing an adequate microenvironment for iron reduction and generating the proton motive force for ion uptake (Dell'Orto et al., 2000). Yet despite these benefits, there is wide diversity in the extent and plasticity of rhizosphere acidification among plant species.

Received for publication 13 Mar. 2015. Accepted for publication 26 May 2015.

This material is based upon work that is supported by the National Institute of Food and Agriculture, U.S. Department of Agriculture, under award number 2009-02533.

${ }^{1}$ To whom reprint requests should be addressed; e-mailrld@ufl.edu.
Herbaceous and woody species like cucumber (Cucumis sativus), cork oak (Quercus suber), and plum (Prunus cerasifera) are capable of acidifying their rhizosphere by developing or enhancing proton extrusion in response to iron deficiency (Dell'Orto et al., 2000; Gogorcena et al., 2001; Gonzalo et al., 2011). On the other hand, wild apple (Malus baccata) and peach-almond hybrids (Prunus amygdalus $\times$ Prunus persica) are not capable of this response (Gonzalo et al., 2011; Wu et al., 2012). Moreover, some species like grapevine (Vitis vinifera) exhibit intraspecific diversity of responses; 'Cabernet Sauvignon' is capable of acidifying its rhizosphere whereas 'Balta' is not (Jimenez et al., 2007; Ksouri et al., 2006).

Although iron reduction and uptake by Vaccinum sp. have been investigated previously (Darnell and Cruz-Huerta, 2011; Poonnachit and Darnell, 2004), to our knowledge rhizosphere acidification in Vaccinium has not been quantified. Southern highbush blueberry, like all cultivated blueberry, is adapted to acidic soils (Coville, 1910; Finn et al., 1993) and experiences iron deficiency when grown in higher $\mathrm{pH}$ soils (Gough, 1997). On the other hand, VA is a wild species that exhibits greater tolerance to high $\mathrm{pH}$ soils (Lyrene, 1997) and greater efficiency at iron assimilation than SHB (Darnell and Cruz-Huerta, 2011).

Additionally, VA and SHB also differ in their ability to take up nitrate from the soil. Several studies indicate that VA exhibits greater nitrate assimilation than SHB (Darnell and Cruz-Huerta, 2011; Darnell and Hiss, 2006; Poonnachit and Darnell, 2004). Since nitrate anions are transported across the PM in symport with $\mathrm{H}^{+}$(Pii et al., 2014; Santi et al., 2003), nitrate uptake in Vaccinium sp. could lead to $\mathrm{pH}$ increases in the rhizosphere, as it does in other woody plants (Jimenez et al., 2007; Sas et al., 2003). Hence, iron and nitrate uptake are closely related due to the antagonistic effect that these processes have on rhizosphere $\mathrm{pH}$.

This study investigated the rhizosphere acidification capacity of two taxa in the genus Vaccinium-V. corymbosum interspecific hybrid (SHB) and VA. We hypothesized that a) SHB and VA would respond to iron deficiency by developing or enhancing rhizosphere acidification beyond levels necessary to offset the effect of nitrate uptake on $\mathrm{pH}$, and b) VA has greater ability to acidify the rhizosphere than SHB and therefore is adapted to a wider range of soil conditions.

\section{Materials and Methods}

Plant material and growth conditions. About 1-year-old rooted cuttings of SHB 'Emerald' and the VA genotype FL09-502 were individually transplanted to 2-L bottles filled with continuously aerated nutrient solution. Plant size was uniform at the beginning of the experiment, with no differences in initial plant fresh weights $($ mean $=83.3 \mathrm{~g}$ ). The nutrient solution contained: $1.0 \mathrm{~mm}$ $\mathrm{KNO}_{3}, 0.5 \mathrm{~mm} \mathrm{~K} \mathrm{PO}_{4}, 1.0 \mathrm{~mm} \mathrm{MgSO}_{4}$, $0.5 \mathrm{~mm} \mathrm{CaCl} 2,0.045 \mathrm{~mm} \mathrm{H}_{3} \mathrm{BO}_{3}, 0.01 \mathrm{~mm}$ $\mathrm{MnSO}_{4}, 0.1 \mathrm{~mm} \mathrm{ZnSO}$ with $0.3 \mu \mathrm{M} \mathrm{CuSO}_{4}$, and $0.2 \mu \mathrm{M} \mathrm{Na}_{2} \mathrm{MoO}_{4}$, and was changed weekly to maintain nutrient concentrations. Plants were acclimated to the hydroponic system in a nutrient solution buffered to $\mathrm{pH}$ 5.5 with $5.0 \mathrm{~mm}$ 2-(4-morpholino)-ethane sulfonic acid (MES). During acclimation, iron concentration in the nutrient solution was $45 \mu \mathrm{M}$ for all plants. Iron was supplied in the form of Sequestrene 330 (10\% Fe (III)diethylenetriamine pentaacetic acid) (Becker Underwood, Inc., Ames, IA). After 14 d, onehalf of the plants received $10 \mu \mathrm{M}$ iron (lower iron) and the other half received $90 \mu \mathrm{m}$ iron (higher iron) in their nutrient solutions. The initial $\mathrm{pH}$ of the nutrient solutions was adjusted to 5.5 for each weekly change, but solutions were prepared without MES to document $\mathrm{pH}$ changes in the rhizosphere starting on day 14 as well.

After $56 \mathrm{~d}$ of treatment ( $70 \mathrm{~d}$ in total), subjective interveinal chlorosis ratings of the plants were made on a scale of 1 to 5 , where 5 was completely green, and decreasing rating levels showed increasing interveinal chlorosis with 1 being severely chlorotic. Following this, plants were destructively harvested, leaves, canes, and roots were separated and weighed, then dried at $72{ }^{\circ} \mathrm{C}$ to a constant weight before further analysis.

Rhizosphere $\mathrm{pH}$. The $\mathrm{pH}$ of the nutrient solution in each bottle was measured three times per week using an Accumet AP110 portable $\mathrm{pH}$ meter (Thermo Fisher Scientific, Inc., Waltham, MA). 
At the end of the experiment (day 70), a representative root sample $(1.4 \%$ of root fresh weight on average) was removed from each plant. A representative root sample included a root of third order or higher and all its attached lower order roots. Root order was determined as per Valenzuela-Estrada et al. (2008). Root samples were rinsed in $1.0 \mathrm{~mm}$ ethylenediaminetetraacetic acid for $5 \mathrm{~min}$ to remove any extracellular iron. Samples were then rinsed in ultrapure water (pH 4.6) three times and blotted dry before embedding in reactive gels. Gels contained $2.2 \mathrm{~mm}$ bromocresol purple ( $\mathrm{pH} 6.0$ ) and 6.25 $\mathrm{g} \cdot \mathrm{L}^{-1}$ low-melting point agarose (adapted from Marchner et al., 1982). Pea (Pisum sativum) seeds were germinated in tissue paper that had been moistened with tap water starting on day 63 . On day 70 , pea roots were used as positive controls for the reactive gels (White and Robson, 1989). Embedded Vaccinium and pea roots were incubated in the dark at room temperature and photographed on a light table 0,6 , and $24 \mathrm{~h}$ after gel set.

Iron and nitrate uptake. Iron and nitrate uptake were measured as depletion from the nutrient solution during all but one of the weeks during the treatment period. Iron concentration in the nutrient solution samples was determined via inductively coupled plasma-atomic emission spectrometry (U.S. Environmental Protection Agency, 1994). Nitrate concentration in the nutrient solution was determined as per Darnell and Cruz-Huerta (2011). Briefly, $10 \mu \mathrm{L}$ of the nutrient solution were diluted in $1.5 \mathrm{~mL}$ of ultrapure water and acidified with $15 \mu \mathrm{L} 12 \mathrm{~N} \mathrm{HCl}$. The absorbance of this dilution at $210 \mathrm{~nm}$ was measured (Biotek Synergy HT; Biotek Instruments, Inc., Winooski, VT) and used to determine nitrate concentration with a standard curve.

Tissue chlorophyll and mineral content. Chlorophyll content was determined from the youngest fully mature leaf of two branches in each plant at the start (day 14) and end (day 70) of the treatment period. Leaf squares (14.5 mg on average) were cut out of each leaf avoiding the leaf edge and midvein. Two leaf squares per plant were pooled and macerated in liquid nitrogen under low light conditions before adding $1.0 \mathrm{~mL} 80 \%$ acetone. Samples were vortexed and centrifuged before reading the absorbance of the liquid phase of the extraction at 645 and $663 \mathrm{~nm}$ (Shimadzu ultraviolet-160, Kyoto, Japan). Chlorophyll content per gram of fresh weight was calculated as per Arnon (1949).

For mineral content determination, dried tissue was ground using a Mini-Mill (Thomas Scientific, Swedesboro, NJ) until it passed through a size of 20 mesh. Total iron content was determined by digesting $0.20 \mathrm{~g}$ of tissue in $4.0 \mathrm{~mL}$ concentrated $\mathrm{HNO}_{3}$ and $0.5 \mathrm{~mL}$ concentrated $\mathrm{HCl}$ for $12 \mathrm{~min}$ at $103{ }^{\circ} \mathrm{C}$ in a rotating microwave. Once samples had cooled to $50{ }^{\circ} \mathrm{C}, 15.5 \mathrm{~mL}$ of deionized water was added for a final dilution of 1:100. Dilutions were filtered and iron content was measured using inductively coupled plasma atomic emission spectrometry (U.S. Environmental Protection Agency, 2007). Active iron content of the dried tissue was determined as per Darnell and Cruz-Huerta (2011). Active iron is the fraction of total iron extracted via digestion in dilute $\mathrm{HCl}$ and is considered a better indicator of the plant's iron status than total iron. About $0.05 \mathrm{~g}$ of tissue was incubated with $1.0 \mathrm{~mL}$ of $0.1 \mathrm{M} \mathrm{HCl}$ for $24 \mathrm{~h}$ under continuous shaking at $11,000 \mathrm{rpm}$. Following incubation, $400 \mu \mathrm{L}$ of the liquid phase were mixed with $250 \mu \mathrm{L}$ of $500 \mathrm{~mm}$ ascorbic acid, $250 \mu \mathrm{L}$ of $1.0 \mathrm{~mm}$ bathopenanthroline (BP), and $400 \mu \mathrm{L}$ of $2.5 \mathrm{~m}$ sodium

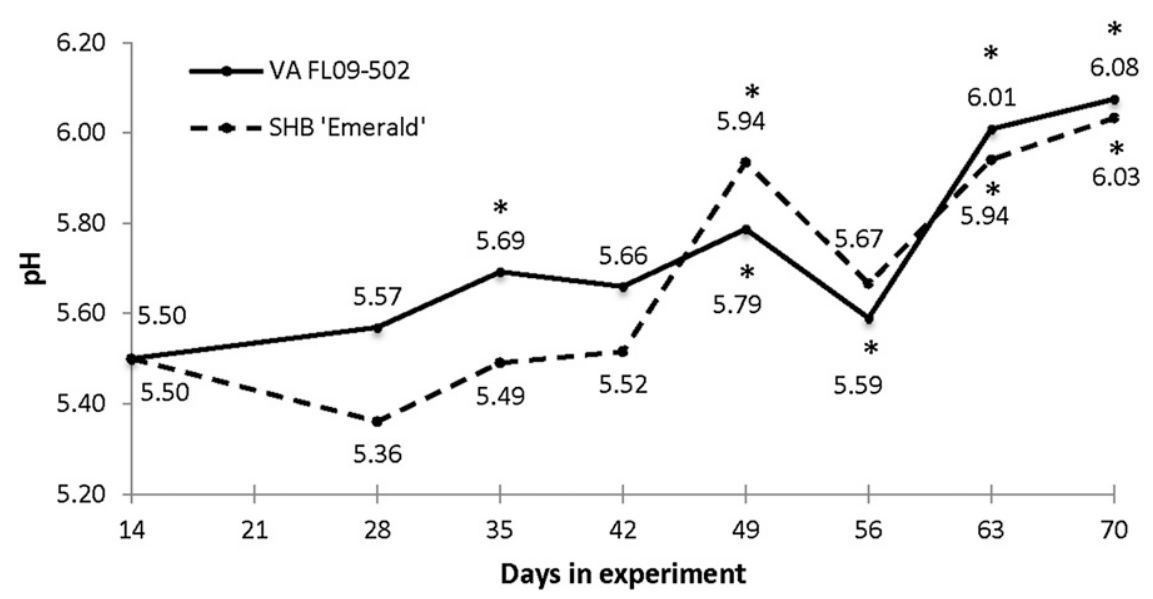

Fig. 1. Nutrient solution pH of hydroponically grown Vaccinium arboreum (VA) FL09-502 (solid line) and southern highbush blueberry (SHB) 'Emerald' (dashed line) for $70 \mathrm{~d}$. Starting on day 14, plants were supplied with fresh, unbuffered nutrient solution (initial $\mathrm{pH} 5.5$ ) with 10 or $90 \mu \mathrm{M}$ iron on a weekly basis. Values shown are means of $n=6$ replications per genotype pooled across iron treatments. Asterisks indicate significant differences from the initial solution $\mathrm{pH}$ as determined by posthoc $t$ tests (Ho: $\mu_{\text {genotype }}=5.5 ; P \leq 0.05$ )
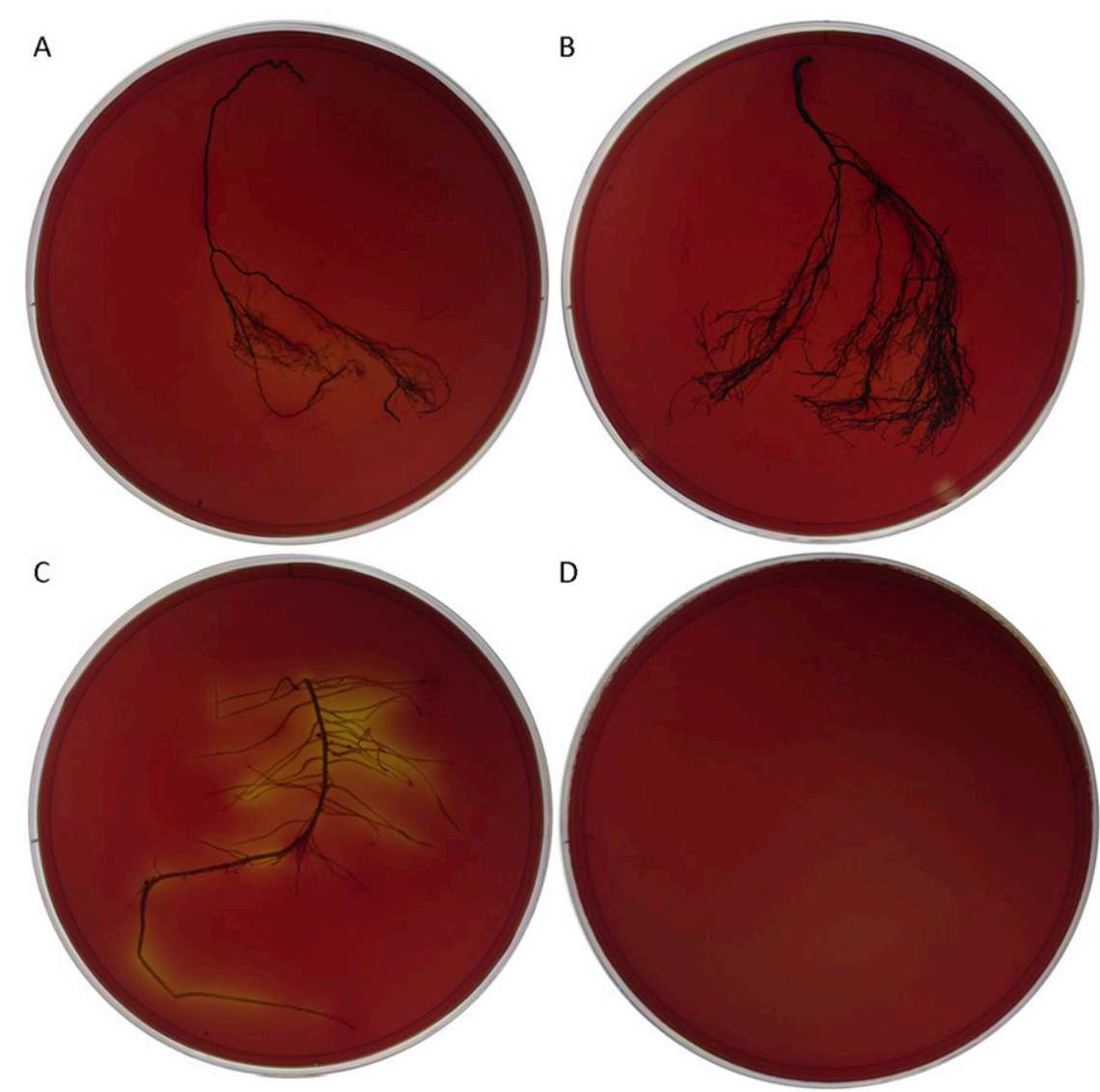

Fig. 2. (A) Southern highbush blueberry 'Emerald', (B) Vaccinium arboreum FL09-502, and (C) Pisum sativum roots embedded in agarose gels containing $\mathrm{pH}$ indicator bromocresol purple ( $\mathrm{pH}$ 6.0). The indicator changes color from purple to red to yellow as the acidity of the medium increases from pH 7.0 to 5.0. (D) Blank gel without roots. No rhizosphere acidification by Vaccinium sp. roots was detected. P. sativum exhibited rhizosphere acidification in its roots. Photographs taken $24 \mathrm{~h}$ after gel set. 
Table 1. Leaf chlorophyll concentration in two Vaccinium genotypes grown hydroponically in nutrient solutions containing 10 or $90 \mu \mathrm{M} \mathrm{Fe}$.

\begin{tabular}{lccc}
\hline & \multicolumn{3}{c}{ Leaf chlorophyll $\left(\mathrm{mg} \cdot \mathrm{g}^{-1}\right.$ fresh wt) } \\
\cline { 2 - 4 } & Day $14^{\mathrm{z}}$ & Day 70 & Difference \\
\hline Genotype $^{\mathrm{z}}$ & 1.40 & 1.48 & $0.08 \mathrm{NS}$ \\
Emerald & 1.00 & 0.88 & $-0.12 \mathrm{NS}$ \\
FL09-502 & $0.40^{*}$ & $0.60 \mathrm{NS}$ & \\
Difference & & & $-0.36^{*}$ \\
Fe concentration $(\mu \mathrm{M})$ & 1.19 & 1.52 & $0.33 \mathrm{NS}$ \\
90 & 1.20 & 0.84 & \\
10 & $-0.01 \mathrm{NS}$ & $0.68^{*}$ & NS \\
Difference & NS & & \\
Genotype $\times$ Fe concentration & &
\end{tabular}

z'Emerald' southern highbush blueberry and Vaccinium arboreum (FL09-502).

Ns, *Nonsignificant and significant at $P \leq 0.05$.

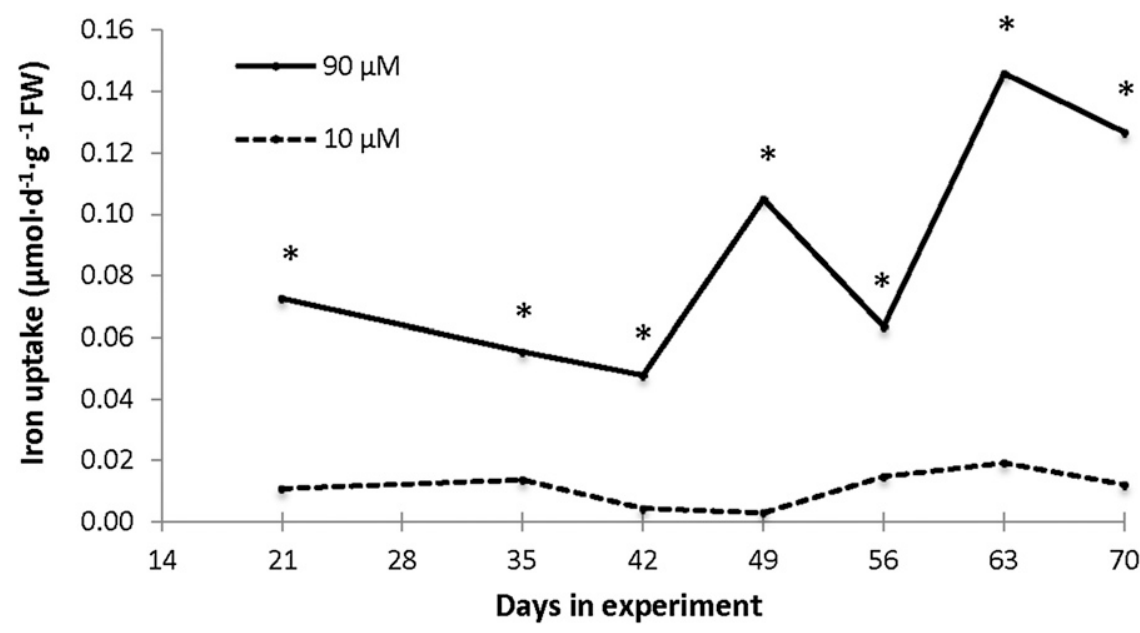

Fig. 3. Iron uptake of hydroponically grown Vaccinium arboreum FL09-502 and southern highbush blueberry 'Emerald' in either $90 \mu \mathrm{M}$ (solid line) or $10 \mu \mathrm{m}$ iron (dashed line). Values shown are means of $\mathrm{n}=6$ replications per iron treatment pooled across genotypes. Asterisks indicate significant differences at $P \leq 0.05 . \mathrm{FW}=$ fresh weight.

Table 2. Total and active iron concentrations in leaves, canes, and roots of two Vaccinium genotypes grown hydroponically for $70 \mathrm{~d}$ in nutrient solutions containing 10 or $90 \mu \mathrm{M} \mathrm{Fe}$.

\begin{tabular}{|c|c|c|c|c|c|c|}
\hline & \multicolumn{3}{|c|}{ Total iron $\left(\mu \mathrm{g} \cdot \mathrm{g}^{-1}\right.$ dry wt $)$} & \multicolumn{3}{|c|}{ Active iron $\left(\mu \mathrm{g} \cdot \mathrm{g}^{-1}\right.$ dry wt) } \\
\hline & Leaves & Canes & Roots & Leaves & Canes & Roots \\
\hline \multicolumn{7}{|l|}{ Genotype $^{z}$} \\
\hline Emerald & 89.27 & 78.50 & 500.50 & 20.43 & 26.03 & 152.19 \\
\hline FL09-502 & 87.50 & 105.25 & 666.36 & 29.29 & 30.40 & 150.92 \\
\hline Difference & $1.77 \mathrm{NS}$ & $-26.75 \mathrm{NS}$ & $-136.86 \mathrm{NS}$ & $-8.86 \mathrm{NS}$ & $-4.37 \mathrm{NS}$ & $1.27 \mathrm{Ns}$ \\
\hline \multicolumn{7}{|l|}{ Fe concentration $(\mu \mathrm{M})$} \\
\hline 90 & 98.64 & 90.58 & 759.45 & 31.02 & 29.01 & 159.99 \\
\hline 10 & 78.92 & 93.17 & 415.17 & 18.70 & 27.30 & 143.12 \\
\hline Difference & $19.72 *$ & $-2.59 \mathrm{NS}$ & $344.28 *$ & $12.32 *$ & $1.71 \mathrm{NS}$ & $16.87 *$ \\
\hline Genotype $\times \mathrm{Fe}$ concentration & NS & NS & NS & NS & NS & NS \\
\hline
\end{tabular}

z'Emerald' southern highbush blueberry and $V$. arboreum (FL09-502).

Ns, *Nonsignificant and significant at $P \leq 0.05$.

acetate ( $\mathrm{pH} 4.5)$. After adding $500 \mathrm{~mL}$ of 1 octanol, the $\mathrm{Fe}^{2+}-\mathrm{BP}$ complex was allowed to migrate to the octanol fraction for $30 \mathrm{~min}$ at room temperature. Finally, the absorbance of the octanol fraction was read at $537 \mathrm{~nm}$. A standard curve was used to quantify the active iron content in the samples.

The total nitrogen content of the sample was determined by combustion of $\approx 0.15 \mathrm{~g}$ of tissue under high-purity oxygen at $850{ }^{\circ} \mathrm{C}$ and subsequent quantitation by thermal conductivity detection (Association of Analytical Communities, 2012) in a LECO FP628 in- strument (LECO Corporation, St. Joseph, MI). To extract nitrate, $0.50 \mathrm{~g}$ of tissue was mixed with $20-\mathrm{mL} 2.0 \mathrm{~N} \mathrm{KCl}$ and incubated for $30 \mathrm{~min}$ under continuous shaking. Extracts were then filtered and the nitrate concentration of the samples was determined using the automated cadmium reducing method (American Public Health Association, 2000) in a Lachat QuikChem 8000 Series Flow Injection Analysis System (Hatch Company, Loveland, CO).

Intra-specific variation. In a subsequent experiment, a wider pool of SHB and VA genotypes was screened for rhizosphere
acidification.Rooted cuttings of SHB 'Abundance', 'Chickadee', 'Farthing', 'Jewel', 'Kestrel', 'Meadowlark', 'Primadonna', 'Snowchaser', and 'Springhigh', eight VA plants (four seedlings and four rooted cuttings) grown from open-pollinated seed, and one micropropagated VA genotype (North American Plants, Inc., Lafayette, OR) were used for this experiment. Rooted cuttings of 'Emerald' and FL09-502 were included as control plants. On average, plants were $13.7 \mathrm{~g}$ (fresh weight) at the start of the experiment. Plants were transplanted to 2-L bottles and acclimated to the hydroponic growth system as described above. Iron concentration was maintained at $45 \mu \mathrm{M}$ for the duration of the experiment. Starting on day 14, buffer MES was withheld from the nutrient solution and $\mathrm{pH}$ was measured three times each week. On day 28 , representative root samples from each plant were embedded in reactive gels containing $\mathrm{pH}$ indicator bromocresol purple. This gel-based method has been successfully used by others to investigate the withinspecies variability in rhizosphere acidification (Santi and Schmidt, 2009).

Statistical analysis. Treatments were arranged in a $2 \times 2$ factorial (genotype $\times$ iron concentration) in a randomized complete block design with six replications, using a single plant per replication. The $\mathrm{pH}$ data collected at the midpoint between solution changes (4th d of every week) were used to fit a general linear mixed model with repeated measurements. Time (measured in weeks) was the quantitative variable, and genotype, iron treatment, and their interaction were the qualitative variables. The interaction term was sliced to test the effect of iron within a genotype. Post-hoc $t$ tests were used to compare the nutrient solution $\mathrm{pH}$ change each week with the initial $\mathrm{pH}$ of 5.5. All data were analyzed using the SAS software (version 9.3; SAS Institute, Cary, NC).

\section{Results}

Rhizosphere acidification. The nutrient solution pH of 'Emerald' and FL09-502 measured midway between solution changes increased gradually during the treatment period in both species (Fig. 1) and in both iron treatments (data not shown). When data were fit to a general linear mixed model, only time was a significant predictor of nutrient solution $\mathrm{pH}$ change $(P<0.001)$. Neither genotype $(P=0.11)$, iron concentration $(P=0.33)$, nor the sliced interaction of species $\times$ iron $(P=0.06$ for 'Emerald', $P=0.37$ for FL09-502, respectively) significantly affected the $\mathrm{pH}$ change of the nutrient solution. On average, nutrient solution $\mathrm{pH}$ increased by $\approx 0.07$ units each week.

Roots of 'Emerald' and FL09-502 embedded in $\mathrm{pH}$-reactive gels for $24 \mathrm{~h}$ did not exhibit rhizosphere acidification, regardless of iron treatment (Fig. 2A and B). Pea roots, which were used as a positive control, acidified the gels (Fig. 2C) within $30 \mathrm{~min}$. Gels with no roots did not change color (Fig. 2D). 
Plant growth. At the beginning of the treatment period (day 14), chlorophyll concentration in 'Emerald' leaves was significantly greater than in FL09-502 leaves (Table 1). However, there were no significant differences between genotypes at day 70 . At the beginning of the treatment period, leaves of plants grown in 10 and $90 \mu \mathrm{M} \mathrm{Fe}$ in the nutrient solution exhibited similar chlorophyll concentrations. By the end of the treatment period, leaves of plants grown under lower iron concentrations contained significantly less chlorophyll than those of plants grown under higher iron concentrations. The interaction between genotype and iron treatment was not significant $(P=0.66$ at day $14, P=0.63$ at day 70$)$. These findings agree with the subjective interveinal chlorosis assessment made on day 70 , where plants grown in $90 \mu \mathrm{M}$ iron averaged a chlorosis score of 4.0 out of 5 while plants grown in $10 \mu \mathrm{M}$ iron averaged 3.5 out of 5 .

After $70 \mathrm{~d}$ of growth, neither genotype nor iron treatment affected leaf (mean = $3.6 \mathrm{~g})$, root $($ mean $=8.8 \mathrm{~g})$, or whole plant (mean $=23.5 \mathrm{~g})$ dry weights. However, cane dry weight in FL09-502 was significantly greater than that in 'Emerald' (15.5 vs. $11.5 \mathrm{~g}$, respectively, $P=0.04$ ), but cane dry weights were not different between iron treatments.

Iron nutrition. There were no significant differences in iron uptake between FL09-502 and 'Emerald' during the $56 \mathrm{~d}$ treatment period (data not shown). For both genotypes, plants grown under higher iron concentrations exhibited significantly greater iron uptake than plants grown under lower iron concentrations (Fig. 3). The interaction of genotypes $\times$ iron concentration was not significant.

The total iron and active iron concentrations did not differ significantly between the genotypes in any organ at day 70 (Table 2). At this time, leaves and roots of plants grown under $90 \mu \mathrm{M}$ iron exhibited significantly greater total iron and active iron concentrations than those of plants grown under $10 \mu \mathrm{M}$ iron. There was no effect of iron concentration on total or active iron concentration in canes and there was no significant interaction between genotype and iron treatment.

Nitrate nutrition. There was a high degree of plasticity in the nitrate uptake of the two Vaccinium genotypes assayed. 'Emerald' exhibited similar $(21,49,63$, and $70 \mathrm{~d})$ or significantly greater $(35,42$, and $56 \mathrm{~d})$ nitrate uptake than FL09-502 (Fig. 4A). The effect of the iron treatment was equally inconsistent. Plants grown in $90 \mu \mathrm{M}$ iron exhibited significantly greater nitrate uptake than plants grown in $10 \mu \mathrm{M}$ iron only at days 35 and 56 after treatment (Fig. 4B). The interaction of genotype $\times$ iron treatment was not significant.

Leaves, canes, and roots of FL09-502 had significantly greater total nitrogen concentration than those of 'Emerald' (Table 3). Total nitrogen concentration was unaffected by iron treatment or the interaction of genotype $x$ iron (data not shown). Nitrate concentration in

A.

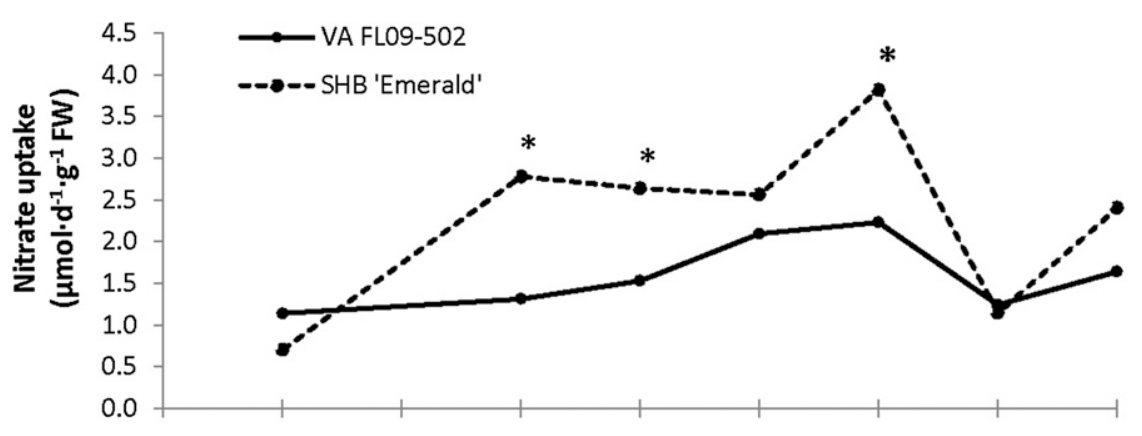

B.

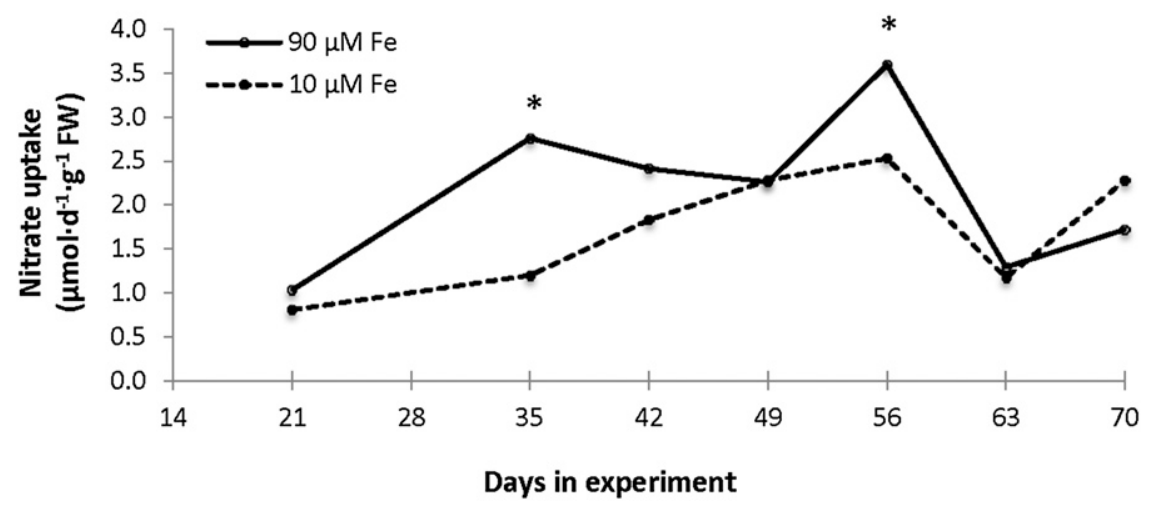

Fig. 4. Nitrate uptake of hydroponically grown Vaccinium arboreum (VA) FL09-502 and southern highbush blueberry (SHB) 'Emerald' in either $90 \mu \mathrm{m}$ or $10 \mu \mathrm{M}$ iron. The interaction of genotype $\times$ iron combination was not significant. Hence, data were pooled by genotype (A) and iron treatment $(\mathbf{B})$. Asterisks indicate significant differences at $P \leq 0.05 ; \mathrm{n}=6 . \mathrm{FW}=$ fresh weight.

Table 3. Total nitrogen and nitrate-nitrogen concentrations in leaves, canes, and roots of two Vaccinium genotypes grown hydroponically for $70 \mathrm{~d}$ in nutrient solutions containing 10 or $90 \mu \mathrm{M} \mathrm{Fe}$.

\begin{tabular}{|c|c|c|c|c|c|c|}
\hline & \multicolumn{3}{|c|}{ Total nitrogen $\left(\mathrm{mg} \cdot \mathrm{g}^{-1}\right.$ dry wt) } & \multicolumn{3}{|c|}{ Nitrate nitrogen $\left(\mu \mathrm{g} \cdot \mathrm{g}^{-1}\right.$ dry wt) } \\
\hline & Leaves & Canes & Roots & Leaves & Canes & Roots \\
\hline \multicolumn{7}{|l|}{ Genotype $^{z}$} \\
\hline Emerald & 15.37 & 5.04 & 8.28 & 8.45 & 7.00 & 20.92 \\
\hline FL09-502 & 21.69 & 7.81 & 12.31 & 3.45 & 4.83 & 22.17 \\
\hline Difference & $-6.32 *$ & $-2.77 *$ & $-4.03 *$ & $5.00 *$ & $2.17 \mathrm{NS}$ & $-1.25 \mathrm{NS}$ \\
\hline \multicolumn{7}{|c|}{ Fe concentration $\left(\mu_{M}\right)$} \\
\hline 90 & 18.88 & 6.48 & 10.50 & 6.45 & 6.33 & 23.17 \\
\hline 10 & 18.48 & 6.38 & 10.08 & 5.45 & 5.50 & 19.92 \\
\hline Difference & $0.40 \mathrm{NS}$ & $0.10 \mathrm{NS}$ & $0.42 \mathrm{NS}$ & $1.00^{*}$ & $0.83 \mathrm{NS}$ & $3.25 \mathrm{NS}$ \\
\hline \multicolumn{7}{|l|}{ Genotype $\times$} \\
\hline Fe concentration & NS & NS & NS & NS & NS & $*$ \\
\hline
\end{tabular}

z'Emerald' southern highbush blueberry and $V$. arboreum (FL09-502).

Ns, *Nonsignificant and significant at $P \leq 0.05$.

leaves of FL09-502 was significantly lower than that in leaves of 'Emerald'. Plants grown under $90 \mu \mathrm{M}$ iron exhibited greater leaf nitrate concentration than the leaves of plants grown under $10 \mu \mathrm{M}$ iron. There were no significant differences in the nitrate concentration of canes and roots. There was a significant interaction between genotype and iron on root nitrate concentration. Roots of 'Emerald' grown under $90 \mu \mathrm{M}$ iron exhibited significantly greater nitrate concentration than roots of 'Emerald' grown under $10 \mu \mathrm{M}$ iron, but they were not significantly different from roots of FL09-502 at either iron concentration (data not shown). All other interactions were not significant.

Intra-specific variation. Nutrient solution $\mathrm{pH}$ increased gradually across all VA and
SHB genotypes tested in the screening study (Fig. 5). The within-species variance was between 0.01 and $0.03 \mathrm{pH}$ units for both species. Representative roots samples of each genotype harvested on day 28 did not change the color of the pH-reactive gels up to $24 \mathrm{~h}$ after gel set (data not shown). Results for pea roots and blanks were similar to those described previously.

\section{Discussion}

Although FL09-502 and 'Emerald' plants grown at both iron concentrations were of similar size and dry weight, plants grown in $10 \mu \mathrm{M}$ iron developed interveinal chlorosis and exhibited reduced chlorophyll, total iron, 


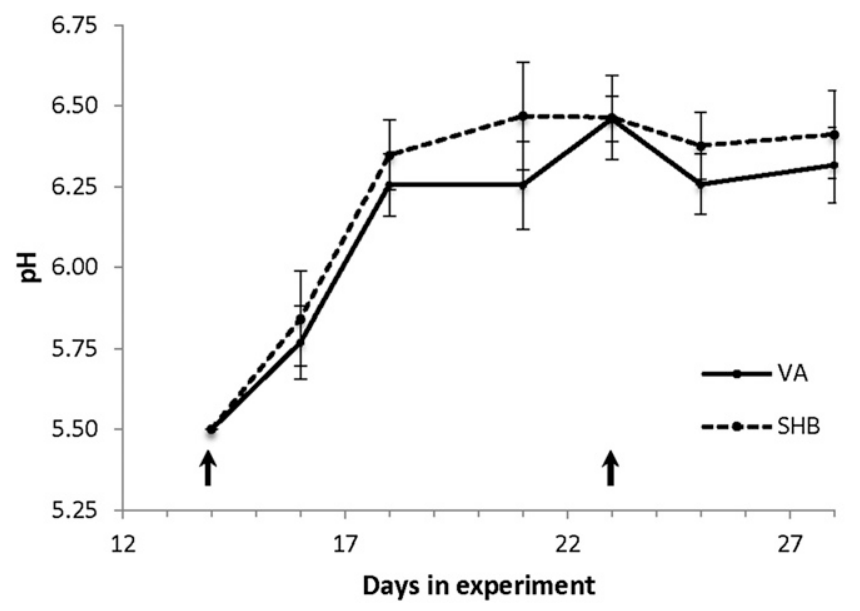

Fig. 5. Nutrient solution $\mathrm{pH}$ of a wide selection of hydroponically grown Vaccinium arboreum (VA) (solid line) and southern highbush blueberry (SHB) (dashed line) genotypes for $28 \mathrm{~d}$. Starting on day 14, plants were supplied with fresh, unbuffered nutrient solution (initial $\mathrm{pH}$ 5.5) on a weekly basis (arrows). Values shown are means of $n=10$ genotypes per species. Vertical bars represent the standard deviation at each data point per species.

and active iron compared with plants grown in $90 \mu \mathrm{M}$ iron. Since these parameters are widely used to diagnose iron deficiency in woody plants (Darnell and Cruz-Huerta, 2011; Gogorcena et al., 2000; Gonzalo et al., 2011; Ksouri et al., 2006), it was expected that if rhizosphere acidification was a strategy employed by these two genotypes, it would be observed in the $10 \mu \mathrm{M}$ iron treatment. However, neither genotype acidified their rhizosphere in response to iron deficiency. In fact, the nutrient solution $\mathrm{pH}$ gradually increased at both higher and lower iron concentrations. Similar absence of acidification has been reported in genotypes in the Malus, Prunus, and Vitis genera (Gogorcena et al., 2000; Gonzalo et al., 2011; Jimenez et al., 2007; Ksouri et al., 2006; Wu et al., 2012).

Given that nitrogen was supplied in the nitrate form, there is a possibility that the observed rhizosphere alkalinization could be a product of $\mathrm{NO}_{3}^{-} / \mathrm{H}^{+}$symport (McClure et al., 1990). VA genotype FL09-502 exhibited lower rates of nitrate uptake than VA genotypes used in previous work (Darnell and Cruz-Huerta, 2011; Poonnachit and Darnell, 2004). Conversely, 'Emerald' took up nitrate at higher rates than observed in other SHB studied previously (Darnell and Cruz-Huerta, 2011; Poonnachit and Darnell, 2004). In this study, both genotypes depleted nitrate from the nutrient solution and raised the nutrient solution $\mathrm{pH}$ to a similar extent. Nitrate uptake by grapevine and strawberry (Fragaria $\times$ ananassa) also led to alkalinization of soil and nutrient solution, respectively (Jimenez et al., 2007; Sas et al., 2003). Hence, nitrate-free reactive gels were used to determine the effects of iron deficiency vs. nitrate uptake on rhizosphere $\mathrm{pH}$. The unchanged color of the reactive gels in this experiment confirmed that neither 'Emerald' nor FL 09-502 extruded protons in response to iron deficiency. Similar results were reported for roots of plum and the Prunus rootstock 'GF677' (Gogorcena et al., 2000; Gonzalo et al., 2011). However, roots of cork oak, strawberry, wild apple, and peach-almond hybrids exhibited rhizosphere acidification in similar gel-based assays (Gogorcena et al., 2001; Gonzalo et al., 2011; Sas et al., 2003; Wu et al., 2012).

In this experiment, VA genotype FL09502 did not take up or contain more iron than 'Emerald', which contrasts with previous work where iron uptake and assimilation increased in VA genotypes compared with SHB (Darnell and Cruz-Huerta, 2011). Given that rhizosphere $\mathrm{pH}$ was above 5.5 for most of the treatment period in this experiment, it is possible that the ability of FL09-502 to assimilate more iron than 'Emerald' was impeded by the unfavorable environment for iron reduction or transmembrane transport (Dell'Orto et al., 2000) provided by the high $\mathrm{pH}$. Previous reports comparing the iron uptake capabilities of VA and SHB used solutions buffered at $\mathrm{pH} 5.5$ (Darnell and Cruz-Huerta, 2011; Poonnachit and Darnell, 2004).

VA genotype FL09-502 took up significantly less nitrate than 'Emerald' and its leaves exhibited significantly lower nitrate concentration than leaves of 'Emerald'. This could be caused by FL09-502 reducing its leaf nitrate pools to compensate for the limited uptake of nitrate in this experiment. However, nitrate reductase activity in $\mathrm{Vacci}$ nium leaves is low or entirely absent (Claussen and Lenz, 1999; Darnell and Hiss, 2006). Alternatively, the low nitrate concentration in the leaves of FL09-502 could be the product of the translocation of already reduced nitrogen from roots to leaves. Previous studies found that VA genotypes exhibited greater root-level nitrate reduction capability than SHB cultivars (Darnell and CruzHuerta, 2011; Poonnachit and Darnell, 2004). However, neither of these scenarios explains the significantly greater total nitrogen concentration in plant organs of FL09502 compared with organs of 'Emerald'. It is possible that FL09-502 had significantly higher total nitrogen concentration in its organs at the start of the experiment, and that the limited nitrate uptake of this genotype did not affect this concentration. Initial nitrogen concentrations were not measured in this experiment.

The nitrate uptake of 'Emerald' relative to FL09-502 is also intriguing. In previous work, VA seedlings exhibited greater nitrate uptake than SHB (Darnell and Cruz-Huerta, 2011; Poonnachit and Darnell, 2004). Since this experiment was carried out with softwood rooted cuttings of VA, it is possible that the discrepancies between our results and those in previous work are due to physiological differences between seedling vs. vegetatively propagated VA. Previous research has identified root-level morphological differences between seedlings and rooted cuttings of lowbush blueberry (Vaccinium angustifolium) (Jamierson and Nickerson, 2003; Morrison et al., 2000). It is possible that root morphological differences may also occur in seedling vs. rooted cuttings of VA. Further work is necessary to determine if this occurs and if so, what effect it would have on nitrogen nutrition.

Considering the reported intraspecific diversity in rhizosphere acidification in other species (Jimenez et al., 2007; Ksouri et al., 2006), a diverse pool of SHB and VA genotypes was screened for this response. When grown in $45 \mu \mathrm{M}$ iron, all genotypes tested failed to acidify the nutrient solution in which they were grown. While there is a possibility that this iron concentration was not low enough to cause iron deficiency, we chose this midrange concentration based on the lack of response to iron concentration observed in the experiment with only FL09-502 and 'Emerald'. The low within-species variances suggest that SHB and VA do not exhibit intraspecific diversity in their rhizosphere acidification. The $\mathrm{pH}$ change in the nutrient solution during this screen was more pronounced than in the previous experiment, despite the smaller size of the plants used, which suggests that size or developmental differences might affect the rhizosphere acidification capacity. Nevertheless, we found no evidence suggesting that any of the SHB or VA genotypes were capable of acidifying their nutrient solution in the reactive gel assay where the sampling method usedbased on root order-accounted for size and developmental differences.

The failure of both VA and SHB to acidify the nutrient solution and the gels suggests that the wider soil adaptation of VA compared with SHB (Hancock et al., 2008; Lyrene, 1997; Lyrene and Brooks, 1995 ) is not related to the former species' capacity to create an acidic microenvironment around its roots. It is tempting to propose that these and other Vaccinium sp. might have lost the ability to acidify their rhizosphere because this trait does not confer a selective advantage in the generally acidic soils where they are found in 
the wild and in cultivation (Coville, 1910; Finn et al., 1993; Lyrene, 1997; Lyrene and Brooks, 1995). In acidic soils, relaxed selection (Lahti et al., 2009) on rhizosphere acidification could have led to the reduction or disappearance of this trait in Vaccinium sp. Alternatively, $\mathrm{H}^{+}$-ATPase mediated rhizosphere acidification has been proposed to be an "emergency" reaction instead of a constitutive part of the iron uptake mechanism (Santi and Schmidt, 2009). Vaccinium sp. did not display this reaction under the experimental conditions despite the development of iron deficiency symptoms. Further investigation of the rhizosphere $\mathrm{pH}$ changes of the members of this genus will be required to discern between these two scenarios.

In conclusion, our results indicate that when grown with nitrate as the sole source of nitrogen, SHB and VA do not respond to iron deficiency by developing or enhancing rhizosphere acidification. SHB 'Emerald' and VA FL09-502 alkalinized their rhizosphere both in higher and lower iron concentrations, which is consistent with nitrate uptake and suggests that rhizosphere acidification is not part of their strategy I iron deficiency response. A screen of additional SHB and VA genotypes confirmed that rhizosphere acidification is not observed throughout these genotypes when nitrate is used as the nitrogen source. In absence of this process, the main driver of rhizosphere $\mathrm{pH}$ for these species is likely to be nitrate uptake.

\section{Literature Cited}

American Public Health Association (APHA). 2000. Protocol 4500-NO3-F. In: Standard methods for the examination of water and wastewater. 21st ed. Amer. Public Health Assn., Amer. Water Works Assn., Water Environ. Federation Publ., Washington, D.C.

Arnon, D.I. 1949. Copper enzymes in isolated chloroplasts: Polyphenoloxidase in Beta vulgaris. Plant Physiol. 24:1-15.

Association of Analytical Communities (AOAC). 2012. AOAC protocol 2.4.02. In: Official methods of analysis of AOAC International. 19th ed. AOAC Intl., Rockville, MD.

Claussen, W. and F. Lenz. 1999. Effect of ammonium or nitrate nutrition on net photosynthesis, growth, and activity of the enzymes nitrate reductase and glutamine synthetase in blueberry, raspberry and strawberry. Plant Soil 208:95-102.

Coville, F. V. 1910. Experiments in blueberry culture. U.S. Dept. Agr. Bul. 193

Darnell, R.L. and S. Hiss. 2006. Uptake and assimilation of nitrate and iron in two $\mathrm{Vacci}$ - nium species as affected by external nitrate concentration. J. Amer. Soc. Hort. Sci. 131:5-10.

Darnell, R.L. and N. Cruz-Huerta. 2011. Uptake and assimilation of nitrate and iron in cultivated and wild Vaccinium species. Intl J. Fruit Sci. 11:136-150.

Dell'Orto, M., S. Santi, P. De Nisi, S. Cesco, Z. Varanini, G. Zocchi, and R. Pinton. 2000 Development of Fe-deficiency responses in cucumber (Cucumis sativus L.) roots: Involvement of plasma membrane H+-ATPase activity. J. Expt. Bot. 51:695-701.

Finn, C.E., J. Luby, C.J. Rosen, and P. Ascher. 1993. Blueberry germplasm screening at several soil $\mathrm{pH}$ regimes I: Plant survival and growth. J. Amer. Soc. Hort. Sci. 118:377-382.

Gogorcena, Y., J. Abadia, and A. Abadia. 2000. Induction of in vivo root ferric chelate reductase activity in fruit tree rootstock. J. Plant Nutr. 23:9-21.

Gogorcena, Y., N. Molias, A. Larbi, J. Abadia, and A. Abadia. 2001. Characterization of the responses of cork oak (Quercus suber) to iron deficiency. Tree Physiol. 21:1335-1340.

Gonzalo, M.J., M.A. Moreno, and Y. Gogorcena. 2011. Physiological responses and differential gene expression in Prunus rootstocks under iron deficiency conditions. J. Plant Physiol. 168:887-893.

Gough, R.E. 1997. Blueberries: North and south. J. Small Fruit Viticult. 4:71-106.

Hancock, J.F., P. Lyrene, C.E. Finn, N. Vorsa, and G.A. Lobos. 2008. Blueberries and cranberries, p. 115-149. In: J.F. Hancock (ed.). Temperate fruit crop breeding. Springer Verlag, Berlin.

Jamierson, A.R. and N.L. Nickerson. 2003. Field performance of the lowbush blueberry propagated by seed, stem cuttings and micropropagation. Acta Hort. 626:431-436.

Jeong, J. and E.L. Conolly. 2009. Iron uptake mechanisms in plants: Functions of the FRO family of ferric reductases. Plant Sci. 176:709-714.

Jimenez, S., Y. Gogorcena, C. Hevin, A.D. Rombola, and N. Ollat. 2007. Nitrogen nutrition influences some biochemical responses to iron deficiency in tolerant and sensitive genotypes of Vitis. Plant Soil 290:343-355.

Kim, S. and M.L. Guerinot. 2007. Mining iron: Iron uptake and transport in plants. FEBS Lett. 581:2273-2280.

Ksouri, R., S. M'rah, M. Gharsalli, and M. Lachaal. 2006. Biochemcial responses to true and bicarbonate-induced iron deficiency in grapevine genotypes. J. Plant Nutr. 29:305-315.

Lahti, D., N. Johnson, B. Ajie, S. Otto, A. Hendry, D. Blumstein, R. Coss, K. Donohue, and S. Foster. 2009. Relaxed selection in the wild. Trends Ecol. Evolution. 24:487-496.

Lemanceau, P., P. Bauer, S. Kraemer, and J. Briat. 2009. Iron dynamics in the rhizosphere as a case study for analyzing interactions between soils, plants and microbes. Plant Soil 321:513-535.

Lyrene, P.M. 1997. Value of various taxa in breeding tetraploid blueberries in Florida. Euphytica 94:15-22.
Lyrene, P.M. and S.J. Brooks. 1995. Use of sparkleberry in breeding highbush blueberry cultivars, p. 29-38. In: R.E. Gough and R.F. Korcak (eds.). Blueberries: A century of research. Food Products Press, Binghamton, NY.

Marchner, H., V. Romheld, and H. OssenbergNeuhaus. 1982. Rapid method for measuring changes in $\mathrm{pH}$ and reducing processes along roots of intact plants. Z. Pflanzenphysiol. 105:407-416.

McClure, P., L.V. Kochian, R.M. Spanswick, and J.E. Shaff. 1990. Evidence for cotransport of nitrate and protons in maize roots. Plant Physiol. 93:290-294.

Morrison, S., J.M. Smagula, and W. Litten. 2000. Morphology, growth, and rhizome development of Vaccinium angustifolium Ait. seedlings, rooted softwood cuttings, and micropropagated plantlets. HortScience 35:738-741.

Pii, Y., M. Alessandrini, K. Guardini, A. Zamboni, and Z. Varanini. 2014. Induction of highaffinity $\mathrm{NO}_{3}$ - uptake in grapevine roots is an active process correlated to the expression of specific members of the NRT2 and plasma membrane H+-ATPase gene families. Funct. Plant Biol. 41:353-365.

Poonnachit, U. and R.L. Darnell. 2004. Effect of ammonium and nitrate on ferric chelate reductase and nitrate reductase in Vaccinium species. Ann. Bot. 93:399-405.

Santi, S. and W. Schmidt. 2009. Dissecting iron deficiency-induced proton extrusion in Arabidopsis roots. New Phytol. 183:1072-1084.

Santi, S., G. Locci, R. Monte, R. Pinton, and Z. Varanini. 2003. Induction of nitrate uptake in maize roots: Expression of a putative highaffinity nitrate transporter and plasma membrane $\mathrm{H}+$-ATPase isoforms. J. Expt. Bot. 54:1851-1864.

Sas, L., H. Marschner, V. Romheld, and S. Mercik. 2003. Effect of nitrogen forms on growth and chemical changes in the rhizosphere of strawberry plants. Acta Physiol. Plant. 25:241247.

U.S. Environmental Protection Agency. 1994. Method 200.7, U.S. Environ. Protection Agency, Washington, D.C.

U.S. Environmental Protection Agency. 2007. Method 6010C, U.S. Environ. Protection Agency, Washington, D.C.

Valenzuela-Estrada, L.R., V. Vera-Carballo, L.E. Ruth, and D.M. Eissenstat. 2008. Root anatomy, morphology and longevity among root orders in Vaccinium corymbosum (Ericaceae). Amer. J. Bot. 95:1506-1514.

White, P. and A.D. Robson. 1989. Rhizosphere acidification and $\mathrm{Fe}^{3+}$ reduction in lupins and peas: Iron deficiency in lupins is not due to a poor ability to reduce $\mathrm{Fe}^{3+}$. Plant Soil 119:163-175

Wu, T., H. Zhang, Y. Wang, W. Jia, X. Xu, X. Zhang, and Z. Han. 2012. Induction of root Fe(III) reductase activity and proton extrusion by iron deficiency is mediated by auxin-based systemic signaling in Malys xiaojinensis. J. Expt. Bot. 63:859-870. 